\title{
Experimental investigation of the effect of engine settings on the wall heat flux during HCCI combustion
}

\author{
Stijn Broekaert ${ }^{\mathrm{a}}$, Thomas De Cuyper ${ }^{\mathrm{a}}$, Michel De Paepe ${ }^{\mathrm{a}}$, Sebastian Verhelst ${ }^{\mathrm{a}}$ \\ ${ }^{a}$ Ghent University, Belgium
}

\begin{abstract}
Homogeneous charge compression ignition (HCCI) engines are a promising alternative to traditional spark- and compression-ignition engines, due to their potential to achieve a high thermal efficiency and near-zero emissions of $\mathrm{NO}_{x}$ and soot. In this work, the heat transfer from the bulk gas to the cylinder wall is measured during motored and HCCI operation in a single cylinder (CFR) engine fueled with n-heptane. Heat flux measurements in the cylinder wall and head show small spatial variation of the heat flux in the combustion chamber. Design of Experiments methods are applied to study the effect of the engine settings on the heat transfer. It is found that the inlet air temperature does not affect the heat flux under motored operation. Under fired operation, all engine settings affect the heat transfer, but none of their interactions are significant. The compression ratio and inlet air temperature have a quadratic effect on the peak heat flux and peak convection coefficient, whereas the mass fuel rate has a linear effect. For the total heat released, the compression ratio and inlet air temperature have a linear effect and the mass fuel rate has a quadratic effect on it. All engine settings affect the instantaneous heat flux.
\end{abstract}

Keywords: Heat transfer, Homogeneous charge compression ignition, internal combustion engine, experimental

\section{Introduction}

In recent years, alternatives to traditional spark- and compression-ignition combustion are being investigated due to increasingly stringent emission legislation combined with the pursuit of a low fuel consumption. One of the alternative 5 combustion principles that has received much interest is homogeneous charge compression ignition (HCCI) 1, 2, which allows achieving both a high thermal efficiency and near-zero emissions of $\mathrm{NO}_{x}$ and soot 3 . This is obtained by the auto-ignition of a lean premixed fuel-air mixture through compression. Because the auto-ignition process is mainly driven by chemical kinetics, the combustion

\footnotetext{
*Stijn Broekaert

Email address: stijn.broekaert@ugent.be (Stijn Broekaert)
} 
10 is very sensitive to the mixture temperature. Hence, the heat transfer from the bulk gas to the walls of the combustion chamber has a large effect on important combustion properties, such as the start of combustion and the burn duration. It also affects the formation of pollutants such as $\mathrm{NO}_{x}$, which have a strong temperature dependent formation process. A lot of research has been 15 conducted on the heat transfer in gasoline and diesel engines [4]. However, despite the importance of the heat transfer in HCCI engines, only a limited number of studies have been performed in which the heat transfer is measured experimentally.

Boggs 8] was the first to investigate the heat flux during HCCI operation.

${ }_{20}$ He used a coaxial type heat flux sensor with 5 surface thermocouples to measure the heat flux at the cylinder head of a CFR (Cooperative Fuel Research) engine. HCCI operation was obtained by heating the inlet air and using ethylene as fuel. The effect of the gas flow on the heat flux was investigated by comparing an unshrouded inlet valve with a shrouded inlet valve at multiple shroud positions.

25 Only the case with a counter clockwise swirl motion produced a significantly

lower heat flux. It was speculated that this was caused by the dissipation of kinetic energy by the spark plug hole. The effect of the combustion was investigated by increasing the mass fuel rate and the inlet air temperature compared to a base setting. Both variations resulted in a higher heat flux.

To be able to construct a heat transfer model for HCCI engines, Chang et al. 9, 10, measured the heat flux in a gasoline fueled single cylinder engine with exhaust rebreathing. Thermocouples were mounted at 7 locations in the piston surface and 2 locations in the cylinder head. The spatial variation of the heat transfer was evaluated by comparing the instantaneous heat flux traces at the different locations and by performing a heat release analysis. They concluded that a local heat flux measurement accurately represents the global heat transfer, unless the fuel preparation caused fuel impingement or stratification. The validation of these results for other operating conditions, revealed that increasing the fuel rate and engine speed also increases the peak heat flux.

40 Hensel et al. [11, 12] measured the heat flux in 2 gasoline fueled singlecylinder engines, also with exhaust rebreathing. The heat flux was measured in one engine with thermocouples mounted at 8 locations in the cylinder head and in the other engine at 3 locations in the cylinder head. They confirmed the conclusion of Chang et al. concerning the spatial variation when changing the 4 injection timing, valve timing and mixture preparation. They also found that the heat flux increases when increasing the load and engine speed and when advancing the injection timing so the combustion occurs earlier.

Finally, Heinle [13] investigated the heat flux in a single cylinder engine fueled with n-heptane. HCCI operation was obtained by heating the inlet air. An 50 exhaust valve was fixed to the cylinder head and equipped with 8 thermocouples to measure the heat flux. He reported an increase in heat flux when the engine speed and inlet temperature were increased and a decrease in heat flux when the inlet pressure and Exhaust Gas Recirculation (EGR) rate were increased.

In current literature, the investigation of the effect of the engine settings on 55 the heat transfer has been limited to comparing the measured heat flux traces 
when varying one engine setting at a time. Opposed to this one-variable-ata-time approach, in this work, measurements are conducted according to the Design of Experiments methodology (DoE) [14, 15. By applying this methodology, it is possible to investigate the effect of the engine settings in a systematic way and to take into account the possible interactions between them. The effect of the compression ratio, mass fuel rate and inlet air temperature on the peak heat flux, the shape of the heat flux trace and the total heat released is investigated.

To separate the effects of the gas flow and the combustion, two experiments

${ }_{65}$ are created: one under motored operation and one under fired operation of the engine. First, the spatial variation of the heat transfer is investigated by comparing heat flux measurements at the cylinder head with measurements at the cylinder wall. The accuracy of the measurements is validated by performing a heat release analysis and by checking whether deposit formation affected

70 the measurements. To determine which engine settings and interactions have a significant effect on the peak heat flux, the ANOVA (analysis of variance) methodology is followed for both motored and fired operation. With the significant parameters found, an experimental surface is constructed showing the magnitude of the effect each engine setting has. The observed results are linked

75 to the underlying physical phenomena by using the convection coefficient to separate the effect of the temperature difference between the gas and the wall from the effect of the gas properties. Finally, the effect of the engine settings on the shape of the heat flux trace is investigated.

\section{Experimental equipment}

The base engine used in this research is a Waukesha CFR engine. This is a standardized, overhead valve, single cylinder, four stroke engine. It is operated at a constant speed of $600 \mathrm{rpm}$ and has an adjustable compression ratio. The engine specifications are listed in Table 1 and a cross section of the cylinder is displayed in Fig. 1 1 showing the possible sensor mounting positions. It is

85 equipped with a programmable MoTeC M4 Pro Engine Control Unit to control the injection timing and duration. To obtain HCCI operation, an air preheating system and a heated external EGR circuit were added. However, no EGR was applied in this work. Fig. 2 shows a scheme of the engine layout. The intake air is heated with a $6 \mathrm{~kW}$ Osram Sylvania inline heater which is controlled by a

90 Gefran 600 Temperature Controller to keep the temperature at the inlet within $0.5^{\circ} \mathrm{C}$ of the set value. The engine is fueled with n-heptane which is injected $180 \mathrm{~mm}$ before the intake valve to attain a homogeneous air-fuel mixture in the cylinder.

The in-cylinder pressure is measured with a water-cooled Kistler 701A piezo-

95 electric sensor (mounted in P2). Inlet and outlet pressure are measured with two water-cooled Kistler 4075A10 piezoresistive pressure sensors. The in-cylinder pressure is referenced with the inlet pressure. The air flow is measured with a Bronkhorst F-106BZ flow sensor and the fuel mass flow rate is measured with a Bronkhorst mini Cori-Flow M13 coriolis mass flow meter. The heat flux and 
Table 1: CFR-engine properties

\begin{tabular}{|c|c|}
\hline Bore & $83.06 \mathrm{~mm}$ \\
\hline Stroke & $114.2 \mathrm{~mm}$ \\
\hline Connecting rod length & $254 \mathrm{~mm}$ \\
\hline Swept volume & $618.8 \mathrm{~cm}^{3}$ \\
\hline IVO & $10^{\circ} \mathrm{ca}$ ATDC \\
\hline IVC & $19^{\circ} \mathrm{ca}$ ABDC \\
\hline EVO & $39^{\circ} \mathrm{ca}$ BBDC \\
\hline EVC & $12^{\circ} \mathrm{ca}$ ATDC \\
\hline
\end{tabular}
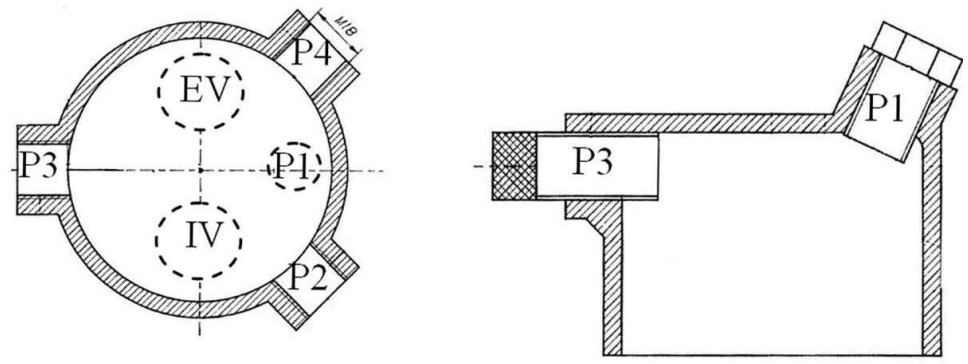

Figure 1: Cross section of the CFR engine, P1-4: possible sensor positions, IV: intake valve, EV: exhaust valve

100

wall temperature are measured with a Vatell HFM-7 sensor mounted in position P1, unless indicated otherwise. The sensor consists of a thermopile (heat flux signal) and an RTD (resistance temperature detector). It has a claimed response time of $17 \mu \mathrm{s}$. A Vatell AMP-6 amplifier is used as a current source for the RTD and as an amplifier for both output signals. The sensor outputs are directly correlated to their measured quantities. The heat flux and wall temperature are obtained by applying the calibration constants supplied by the manufacturer, without further signal processing. Finally, K-type thermocouples are used to measure coolant, oil and inlet and exhaust gas temperatures. A National Instruments PXI data acquisition system is used to sample the pressure and heat flux signals for 100 consecutive cycles. It is triggered by a crank angle encoder every $0.25^{\circ} \mathrm{CA}$, resulting in a sampling rate of $14.4 \mathrm{kHz}$. The other signals are averaged over time and acquired at a sampling rate of $1 \mathrm{~Hz}$.

In the analysis, the peak value of the heat flux and the total heat released are both obtained from the mean heat flux trace of each operating point, which is obtained by taking the ensemble average over 100 consecutive cycles. The convection coefficient is determined according to Eq. 1 .

$$
h=\frac{q}{T_{\text {gas }}-T_{\text {wall }}}
$$

With $\mathrm{h}$ the convection coefficient, $\mathrm{q}$ the instantaneous heat flux, $\mathrm{T}_{\text {gas }}$ the tem- 




Figure 2: Scheme of the engine

perature of the combustion gases and $\mathrm{T}_{\text {wall }}$ the surface temperature. It is calculated for each engine cycle using the measured instantaneous heat flux, wall and gas temperature and subsequently averaged over 100 consecutive cycles. Demuynck et al. [16] demonstrated that the convection coefficient can provide additional insight into the heat transfer process. The convection coefficient can be used to separate the effect of the temperature difference between the gas and the wall from other influencing factors on the heat transfer, as the convection coefficient represents the effect of the gas flow and gas properties (conductivity, viscosity, density and heat capacity). An error analysis was carried out according to the methods described in [17. The worst case values of the relative errors are reported in Table 2

Table 2: Experimental uncertainty

\begin{tabular}{c|c} 
Variable & Relative error \\
\hline Wall temperature & $4 \%$ \\
\hline Heat flux & $5 \%$ \\
\hline Total heat released & $8 \%$ \\
\hline Convection coefficient & $12 \%$
\end{tabular}




\section{Spatial variation}

130 combustion chamber can represent the global heat transfer, as indicated by Chang et al. 9 and Hensel et al. 11. If this is the case, then one measurement of each operating point with the sensor in one location suffices to capture the global heat transfer. If this is not the case, then each operating point needs to be checked by comparing the measured heat flux traces with the sensor mounted at all the available mounting locations: P1-P4 (see Fig. 1). Mounting positions P2$\mathrm{P} 4$ are located at the same height in the cylinder wall and are evenly distributed around the circumference of the cylinder. Mounting position P1 is located in the cylinder head. First the heat flux traces are compared for motored operation.

Under motored operation, no combustion takes place, so the engine acts as a compressor driven by the electric motor. This makes it possible to investigate whether the gas flow causes inhomogeneities in the spatial distribution of the heat transfer. It can be seen in Fig. 3 that the heat flux traces are identical

the heat flux is spatially homogeneous.

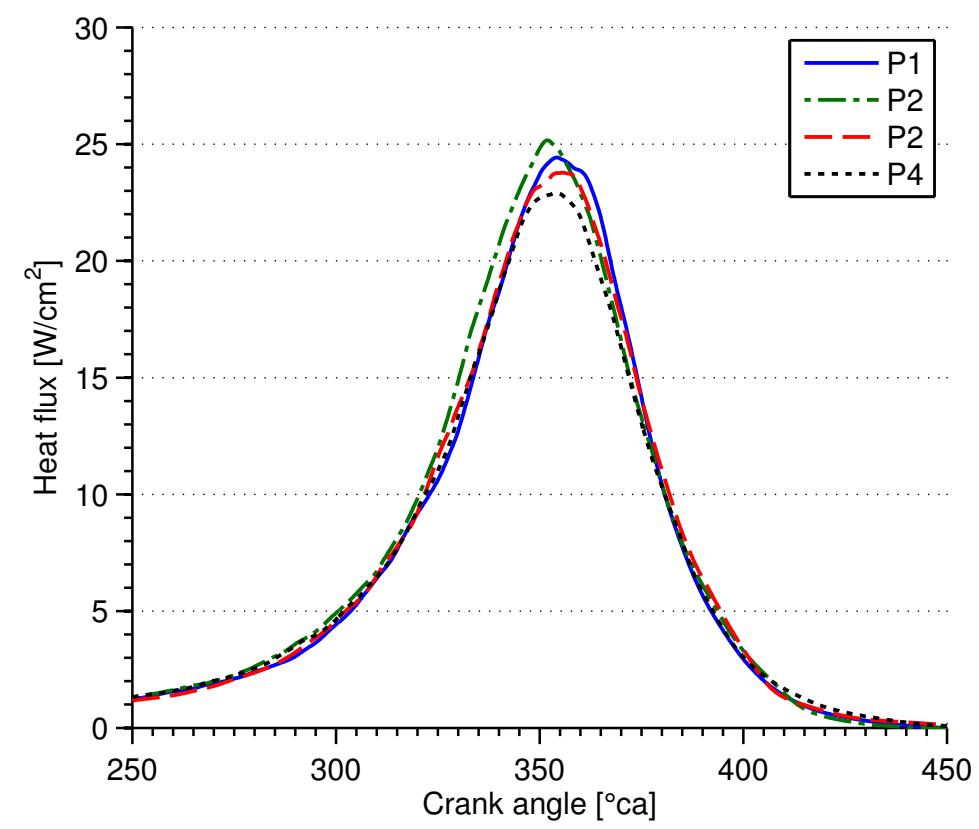

Figure 3: Heat flux at multiple measurement locations during motored operation

The heat flux and convection coefficient traces under fired operation are displayed in Figs. $4 \mathrm{a}$ and $4 \mathrm{~b}$ for a compression ratio of 8 and 10 respectively. The black vertical lines indicate the start and the end of the combustion. During 
150 the combustion, the heat flux measured at the cylinder head (P1) is higher than the heat flux measured at the wall (P2-P4) for both operating points. Since the surface temperature of the cylinder wall and head is the same, the higher heat flux can be attributed to a higher convection coefficient, according to Eq. 1. This means the higher heat flux is caused by a different gas flow near the 155 cylinder head compared to the wall. Because this is only present during the combustion, it is most likely the result of a degree of spatial inhomogeneity of the combustion. Note that the observed spatial variation of the heat flux during HCCI operation is small compared to spark-ignition operation. De Cuyper et al [18 observed four distinctly different heat flux traces during the combustion at ${ }_{160}$ the different measurement positions in a CFR engine operated in spark-ignition mode. This is due to the propagation of a flame front through the combustion chamber in spark-ignition engines, which is absent during HCCI combustion. 


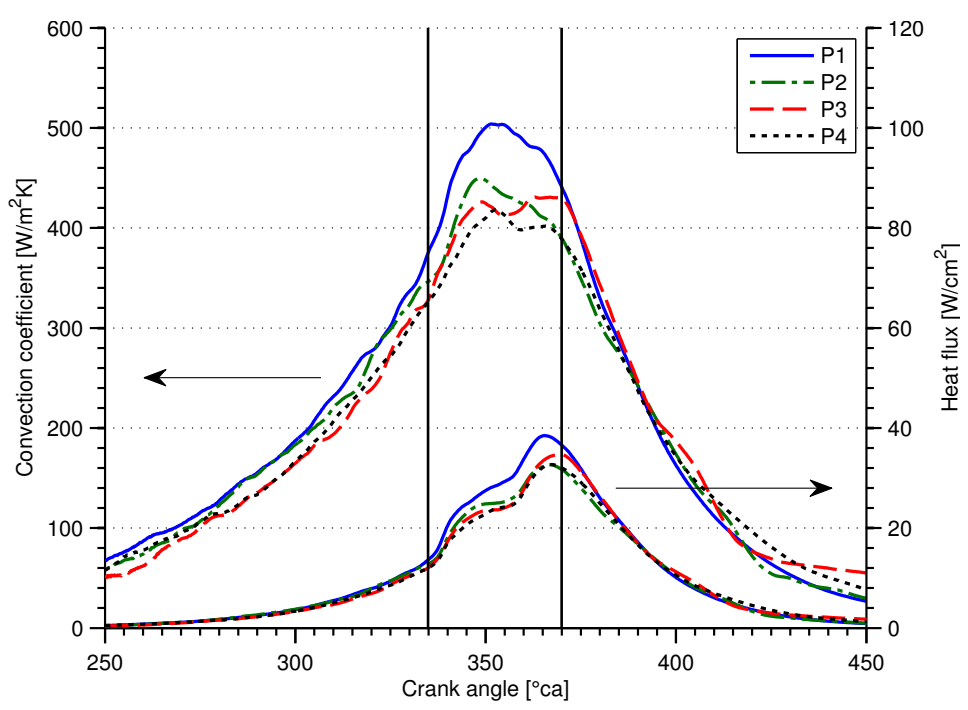

(a) Compression ratio 8

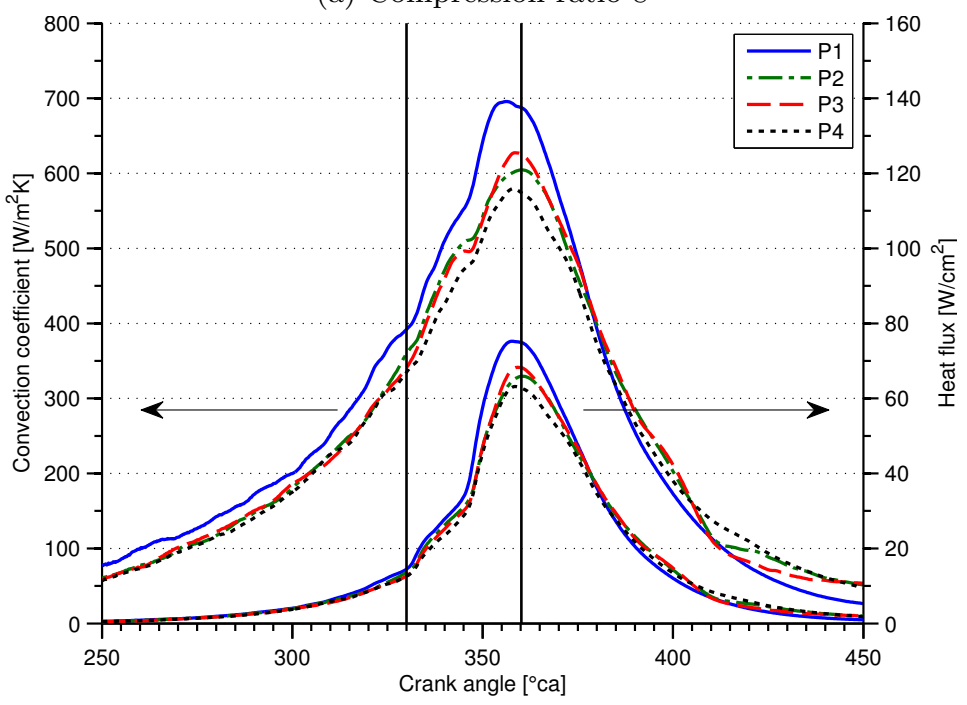

(b) Compression ratio 10

Figure 4: Heat flux and convection coefficient trace at multiple measurement locations during fired operation

Despite the heat flux measured at position P1 being higher than at the other measurement positions, this measurement still accurately represents the global heat transfer. The global heat transfer Q determined with Eq. 2 differs only to a small amount from the one determined with Eq. 3, which only uses the heat flux measured at the head. This is because the difference in heat flux between 
the head and the wall is only present during the combustion, which occurs around top dead center. In this region the instantaneous surface available for heat transfer consists mostly of the piston and cylinder head surface, and only for a small part of the wall surface. Hence the heat flux through the wall is less important around top dead center. This can be seen in Fig. 5 that displays the cumulative global heat transfer determined with Eq. 2 (Qheat,spat full line) and with Eq. 3 (Qheat,P1 dashed line).

$$
\begin{gathered}
Q_{\text {heat }, \text { spat }}=q_{\text {head }} \cdot\left(A_{\text {head }}+A_{\text {piston }}\right)+q_{\text {wall }} \cdot A_{\text {wall }} \\
Q_{\text {heat }, P 1}=q_{\text {head }} \cdot\left(A_{\text {head }}+A_{\text {piston }}+A_{\text {wall }}\right)
\end{gathered}
$$

With Q the global heat transfer, qhead the heat flux measured at the head (P1), $\mathrm{q}_{\text {wall }}$ the spatially averaged heat flux measured at the wall (P2-4), $\mathrm{A}_{\text {piston }}$ the piston surface, $\mathrm{A}_{\text {head }}$ the cylinder head surface and $\mathrm{A}_{\text {wall }}$ the instantaneous wall surface available for heat transfer.

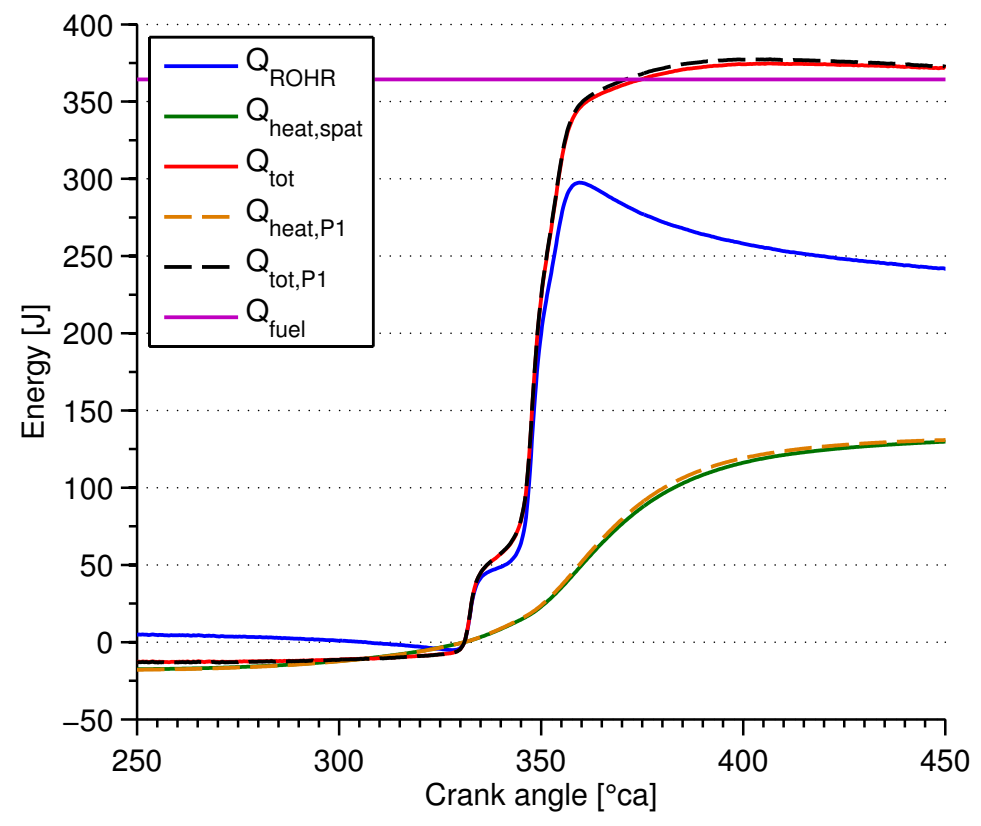

Figure 5: Energy balance during fired operation

Next, a heat release analysis is performed to validate the accuracy of the 180 measurements. In the heat release analysis, the first law of thermodynamics is applied to the combustion chamber, treated as a single-zone, during the closed part of the engine cycle. This allows to construct an energy balance to validate the heat flux measurements. The cumulative net heat release rate added to the cumulative heat transfer should equal the chemical energy of the fuel released 
during the combustion. A more detailed description of the heat release analysis can be found in Appendix A.1 and in 9, 19. In Fig. 5 the cumulative net heat release rate $\mathrm{Q}_{R O H R}$ is shown together with the cumulative heat transfer $\mathrm{Q}_{\text {heat }}$, the sum of both $\mathrm{Q}_{t o t}$ and the released chemical energy $\mathrm{Q}_{\text {fuel }}$. It can be seen that the total energy released equals the chemical energy, which validates the 90 accuracy of the measurements. The released energy is overestimated by about $2 \%$, but this is within the experimental uncertainty. The total energy released is also shown with the cumulative heat transfer determined according to Eq. 3 $\left(\mathrm{Q}_{t o t, P 1}\right)$ in a dashed line. Both traces are identical, demonstrating again that only one heat flux measurement is sufficient to capture the global heat transfer.

\section{Deposit formation}

According to the research of Güralp $20-22$ et al., a layer of deposits can grow on the surface of the combustion chamber during HCCI operation. This is caused by the condensation of fuel or oil on the wall. Such a deposit layer can alter the combustion phasing and burn duration. Also, if this layer grows on the surface of the heat flux sensor, it forms a thermal barrier that can significantly alter the measured heat flux. It dampens the measured temperature swing during combustion and delays the phasing of the peak temperature, causing a reduction of the measured heat flux.

In this work, the effect of deposits on the heat flux sensor is examined by comparing the measured heat flux of replicated measurements. These measurements were carried out with an equal distribution throughout the test day, under both motored and fired operation. The measured heat flux traces are shown in Figure 6. The variation of the heat flux between the different measurements are within the experimental uncertainty. This suggests that no layer of deposits grew on the surface of the heat flux sensor, or had a thickness sufficient to significantly alter the measured heat flux. Also, no significant difference is found when comparing the heat release traces of the replicated measurements. So the combustion was not altered by the presence of deposits on the combustion chamber. A visual inspection of the heat flux sensor after the measurements did not reveal a visible deposit layer either. It can be concluded that deposits did not affect the heat flux measurements. This might be because the time span in which the measurement set was completed ( 5 hours) was insufficient to allow for deposit growth. Güralp et al. only report the deposit layer thickness after 10 hours of continuous operation. 


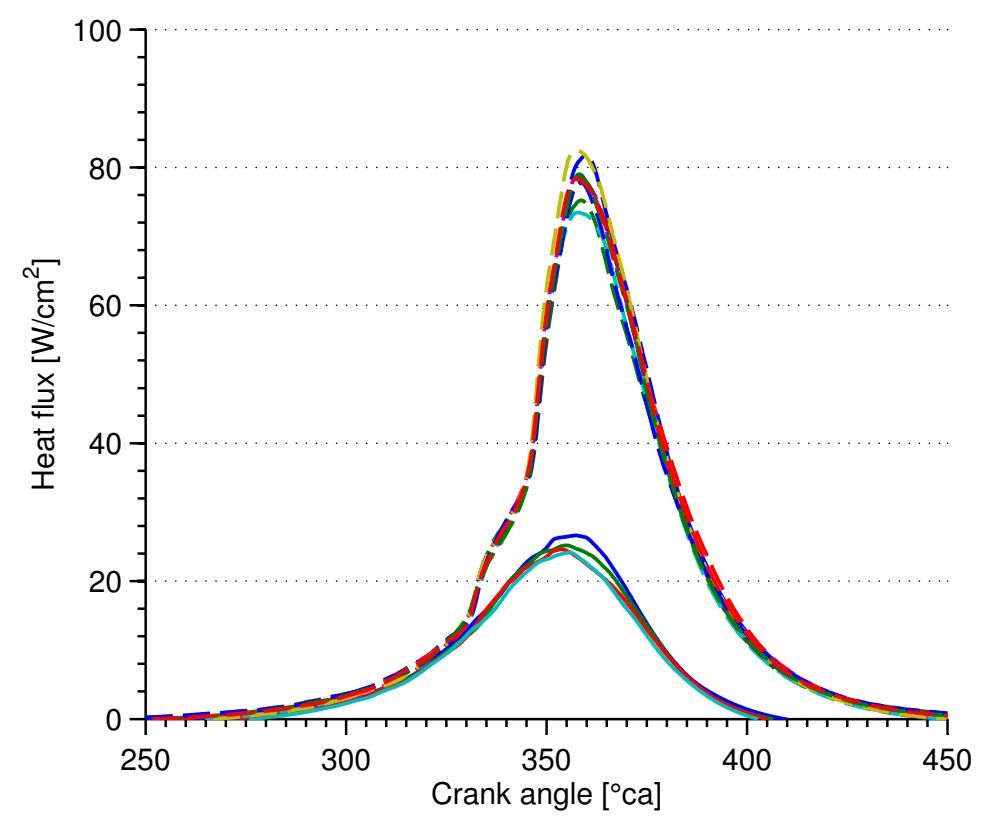

Figure 6: Heat flux for replications of the same operating point under motored (full line) and fired (dashed line) operation

\section{Experimental design}

The experiments in this work are designed and analysed according to Design of Experiments methods. These statistical methods allow investigating the effects of the engine settings in a systematic way and identifying the possible interactions between them. More information about Design of Experiments can found in 14, 15 and applied to spark-ignition engines in 18, 23, 24. account for the possible non-linear effect of certain engine settings, a Response Surface Method (RSM) is applied, which is able to capture quadratic effects. The RSM also provides an experimental surface that visualizes each parameter's effect on the investigated variable. More specifically, a Box-Wilson Central Composite Design is chosen, because it is the RSM design with the best prediction quality across the parameter space. The design is illustrated with Fig. 7 for a 3-factor design. It consists of a full factorial 2-level design (black cubical points) augmented with extreme values of each factor (blue star points) and replications of a base measurement (red center point). The cubical points 235 (levels +1 and -1 ) allow for the identification of main effects and interactions between the factors. The star points (levels +2 and -2 ) identify the non-linear behaviour of each factor and the center point replications (level 0) estimate the experimental error.

To be able to separate the effect of the gas flow from that of the combustion, 


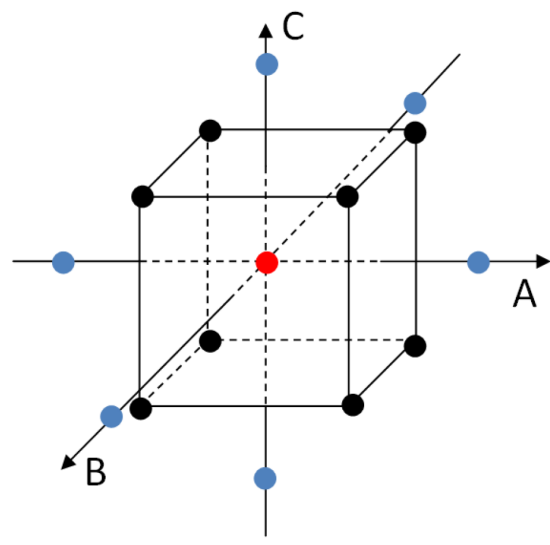

Figure 7: Illustration of the Central Composite Design for 3 factors: A, B and C

operation of the engine. Under motored operation, the inlet air temperature (T) and the compression ratio (CR) are varied. The extreme levels of both factors are listed in Table 3. Under fired operation, the mass fuel rate $\left(\dot{m}_{f}\right)$ is varied, additional to the inlet air temperature and the compression ratio. Their extreme levels are listed in Table 4. These levels are chosen to span the largest possible area of the engine's operating range and to obtain a stable combustion in each operating point. The stable operating range of the engine is illustrated with Fig 8 for different compression ratios. The limits for a stable combustion are: a maximum pressure rise rate less than $3 \mathrm{bar} /{ }^{\circ} \mathrm{ca}$ to avoid ringing combustion 250 and a coefficient of variation less than $5 \%$ to avoid misfire. These constraints allow a variation of $50 \%$ of the inlet air temperature and mass fuel rate. In contrast, the variation of the compression ratio is limited to about $22 \%$. It is not possible to obtain a stable combustion in certain cubical points if a wider range in compression ratio is used. For this reason, two additional measurements are carried out at the extreme levels: one at compression ratio 8 and one at 12 , which corresponds to levels -4 and +4 . The levels of the experiment under motored operation are chosen to correspond with those under fired operation. The center point is replicated three times under motored operation and seven times under fired operation.

Table 3: Overview of the factors' extreme levels under motored operation

\begin{tabular}{c|c|c} 
Factor & Level & Level code \\
\hline \multirow{2}{*}{$\mathrm{T}$} & $80^{\circ} \mathrm{C}$ & -2 \\
& $120^{\circ} \mathrm{C}$ & 2 \\
\hline \multirow{2}{*}{$\mathrm{CR}$} & 8 & -2 \\
& 12 & 2
\end{tabular}


Table 4: Overview of the factors' extreme levels under fired operation

\begin{tabular}{c|c|c} 
Factor & Level & Level code \\
\hline \multirow{2}{*}{$\mathrm{T}$} & $80^{\circ} \mathrm{C}$ & -2 \\
& $120^{\circ} \mathrm{C}$ & 2 \\
\hline \multirow{2}{*}{$\mathrm{CR}$} & 9 & -2 \\
& 11 & 2 \\
\hline \multirow{2}{*}{$\dot{m}_{f}$} & $0.12 \mathrm{~kg} / \mathrm{h}$ & -2 \\
& $0.18 \mathrm{~kg} / \mathrm{h}$ & 2
\end{tabular}



Figure 8: Illustration of the operating range of the engine for different compression ratios

\subsection{Motored operation}

The ANOVA results under motored operation are presented in Table 5 with the peak value of the heat flux as the independent variable. The first column lists the source terms in order of their significance. The second and third column (SS). (SS). The fourth column lists the F-ratio, which is the mean sum of squares of each source term divided by the mean sum of squares of the error term. Because the degrees of freedom is one for each source term, the mean sum of squares equals the sum of squares. The last column contains the p-value indicating the 270 significance of each source term, determined with an F-test. The significant source terms are separated from the insignificant terms with a horizontal line. A significance level of $5 \%$ is employed, meaning only source terms with a p-value 
smaller than 0.05 are considered to have a significant effect. At the bottom of the table, the error term is divided into pure error and lack of fit. The pure error represents the variation present in replicated measurements. With the remaining degrees of freedom, a lack of fit test is performed. A bad model fit can be discovered if the mean sum of squares of the lack of fit is significantly larger than the mean sum of squares of the pure error. Using an F-test, a bad model fit corresponds to a large F-ratio or a small p-value.

280 In this case, the lack of fit test does not indicate a bad model fit. The only significant source term is the main effect of the compression ratio. This indicates that the peak heat flux is a linear function of the compression ratio and the inlet air temperature does not affect it. This can also be seen in Fig. 9. which displays the measured peak heat flux together with the response surface 285 as a function of the compression ratio. The measurements at $90{ }^{\circ} \mathrm{C}, 100^{\circ} \mathrm{C}$ and $110^{\circ} \mathrm{C}$ all coincide at the same compression ratio. The same results are obtained from an ANOVA with the total heat released as the independent variable. It can be concluded that the heat transfer under motored operation is only affected by the compression ratio and not by the inlet air temperature.

290 The temperature difference between the gas and the wall, on the other hand, is affected by both the compression ratio and the inlet air temperature. When the inlet air temperature is increased, the mass air trapped inside the cylinder is reduced as a result of the lower air density. In accordance with the ideal gas law, the gas temperature increases throughout the entire engine cycle, resulting in a 295 larger temperature difference between the gas and the wall. As the heat flux is unaffected by the inlet air temperature, the effect of the increased temperature difference between the gas and the wall must be cancelled out by a decrease of the convection coefficient when the inlet air temperature is increased. Unfortunately, this can not be validated with an ANOVA. The model fails the lack of fit 300 test because the experimental uncertainty is larger than the variation obtained by changing the engine settings. The effect can be explained by looking into the gas properties of air and applying the Reynolds analogy [25. The Reynolds analogy (Eq. 4) is the underlying assumption used in all quasi-state heat transfer models [26, 27, as it describes the convection coefficient as a function of a 305 characteristic length $\mathrm{L}$, a characteristic velocity $\mathrm{V}$, the thermal conductivity $\mathrm{k}$ of the gas, the dynamic viscosity $\mu$ and the density $\rho$ :

$$
h=a \cdot V^{b} \cdot L^{b-1} \cdot k \cdot \mu^{-b} \cdot \rho^{b}
$$

If these gas properties are evaluated at top dead center, the thermal conductivity and dynamic viscosity increase and the density decreases when the inlet air temperature is increased. Assuming the characteristic length and velocity are constant when varying the inlet air temperature and applying a value between 0.5 and 0.8 for the exponent b, as suggested by Reynolds [25], Annand [26] and Woschni [27, the convection coefficient at top dead center decreases. It decreases with about the same amount as the temperature difference between the gas and the wall increases, hence nullifying the effect of the inlet air temperature on the peak heat flux. When the compression ratio is increased, on the 
other hand, the gas temperature increases as well but the air mass trapped in the cylinder remains almost constant. This leads to both a higher temperature difference between the gas and the wall and a higher convection coefficient due to the increased density of the air at top dead center. Despite the compounded effect of the temperature difference and the convection coefficient, the effect of the compression ratio on the heat flux is linear within the current range of the compression ratio.

Table 5: ANOVA table for motored operation

\begin{tabular}{c|c|c|c|c} 
Source term & $\mathrm{DF}$ & $\mathrm{SS}$ & $\mathrm{F}$ & $\mathrm{p}$ \\
\hline $\mathrm{CR}$ & 1 & 104.95 & 71.97 & 0.00 \\
\hline $\mathrm{T} \cdot \mathrm{T}$ & 1 & 2.71 & 1.86 & 0.23 \\
$\mathrm{CR} \cdot \mathrm{T}$ & 1 & 0.26 & 0.18 & 0.69 \\
$\mathrm{CR} \cdot \mathrm{CR}$ & 1 & 0.08 & 0.05 & 0.82 \\
$\mathrm{~T}$ & 1 & 0.01 & 0.00 & 0.96 \\
\hline Lack of fit & 3 & 4.66 & 1.18 & 0.49 \\
Pure error & 2 & 2.63 & & \\
Total error & 5 & 7.29 & &
\end{tabular}

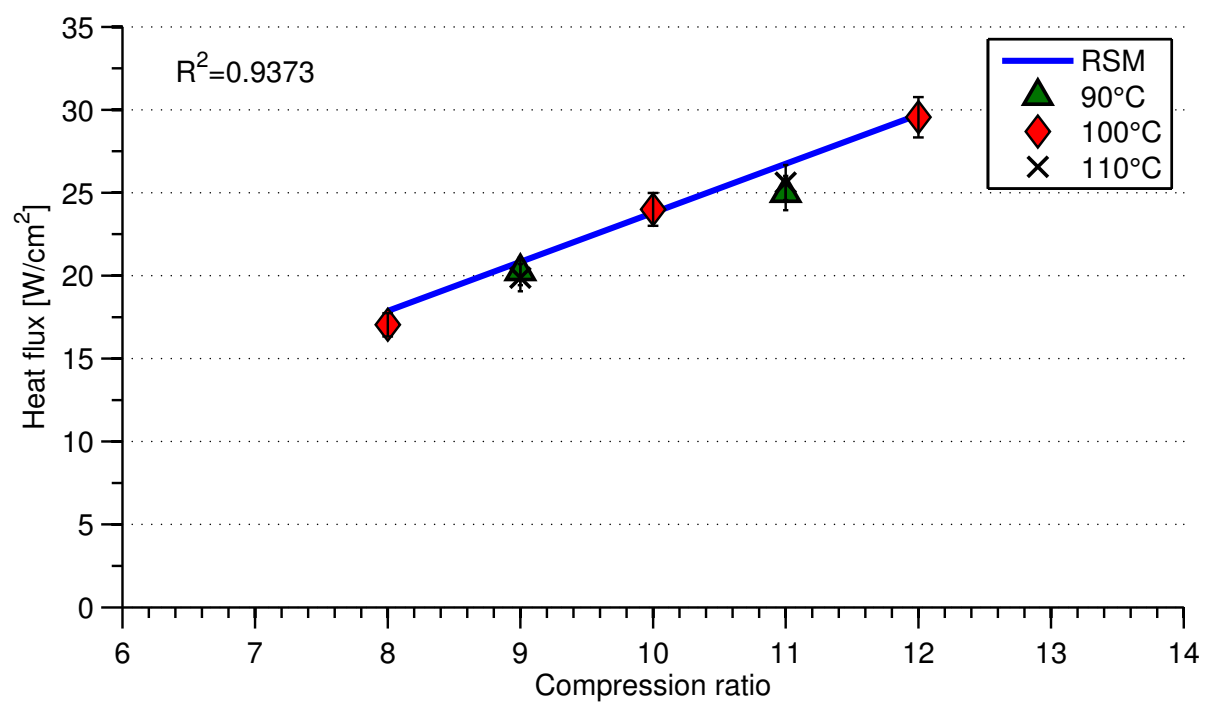

Figure 9: The peak heat flux as a function of the compression ratio for different inlet air temperatures

\subsection{Fired operation}

The ANOVA results for the peak heat flux under fired operation are pre325 sented in Table 6. It can be seen seen from the ANOVA table that the mass fuel rate, compression ratio and inlet air temperature have a significant effect 
on the peak heat flux. Because only the main term of the mass fuel rate is significant, the mass fuel rate has a linear effect on the peak heat flux. Both the compression ratio and the inlet air temperature, on the other hand, have a quadratic effect. None of the interactions between the engine settings are found to be significant.

Increasing the compression ratio or inlet air temperature advances the start of the combustion due to the higher gas temperature during the compression stroke. The advanced combustion itself further increases the cylinder pressure 335 and, consequently, the gas temperature leading to an increased heat flux. The higher gas temperature due to the advanced combustion overcomes the effect of the reduced density on the convection coefficient when the inlet air temperature is increased. It also amplifies the effect of the compression ratio on the heat flux. Increasing the mass fuel rate, on the other hand, increases the energy content of the air-fuel mixture, but does not significantly advance the combustion. As a result, its effect on the peak heat flux is smaller. The obtained response surface for each engine setting is shown in Fig. 10 together with experimental data. The variation of each engine setting is shown around the center point. Since no interactions are significant, the shape of the surface will not change if 345 other engine settings are changed. Only its mean value will change. The overlap between the modelled surface and the measurement data indicates a good model fit. Notice that the figures contain experimental data points at levels +1 and -1 around the center point for the mass fuel rate and at level +4 for the inlet air temperature. These data points were not included in the original design and were not used to fit the model, so they further validate the good model fit. The fact that the interactions are not significant is illustrated with Fig. 11. It shows the variation of the measured peak heat flux as a function of the mass fuel rate for different settings of the compression ratio and inlet air temperature. The lines are added as guide to the eye. It can be seen that the slopes are the same 355 for each setting of compression ratio and inlet air temperature. This means that the variation of the peak heat flux with mass fuel rate is not affected by the other engine settings, so no interactions with the mass fuel rate are present. The compression ratio and inlet air temperature do change the mean value, indicating they themselves have an effect on the peak heat flux. An ANOVA is also performed for the peak convection coefficient and the total heat released. In the case of the peak convection coefficient, the same source terms as for the peak heat flux are significant. For the total heat released however, all the main effects are significant combined with the quadratic effect of the mass fuel rate. The larger contribution of the mass fuel rate can be explained by the larger energy content of the mixture. Since more energy is released during the combustion, more of this energy is lost as heat to the walls.

\subsection{Instantaneous heat flux}

Opposed to motored operation, the engine settings change the shape of the heat flux trace under fired operation. The combustion timing is altered, which

370 also affects the heat flux. To capture the effect of the engine settings on the shape of the heat flux trace, the crank angle is added as an extra factor to the 


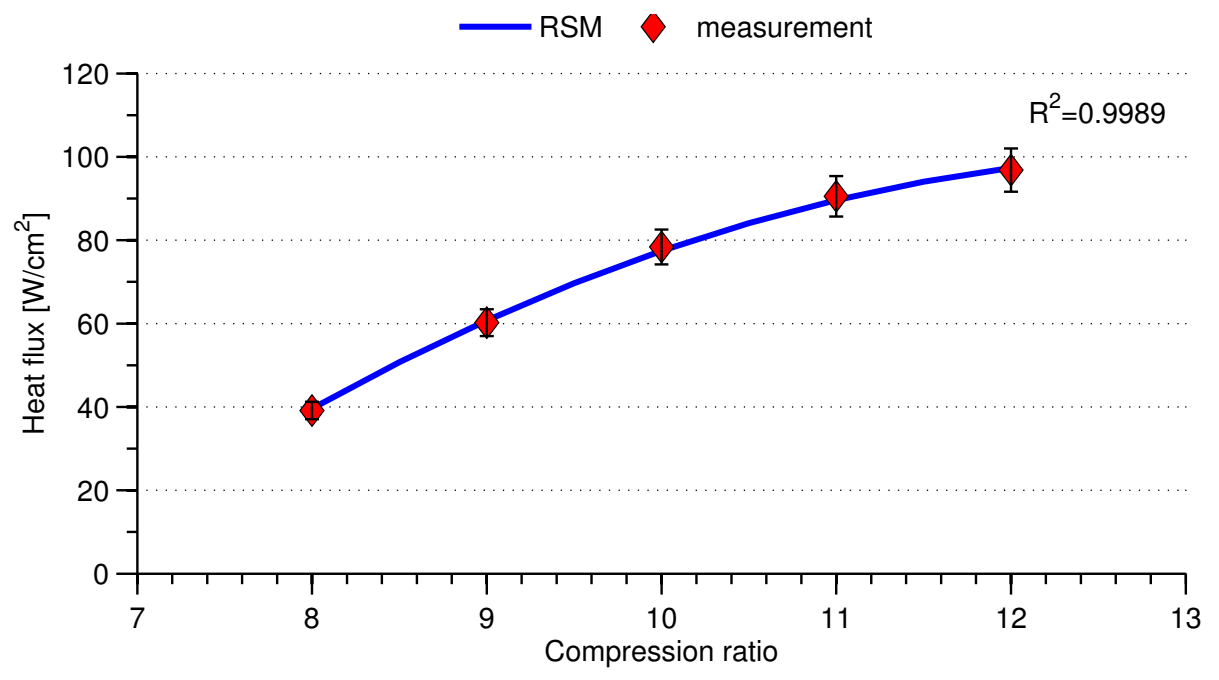

(a) Effect of the compression ratio

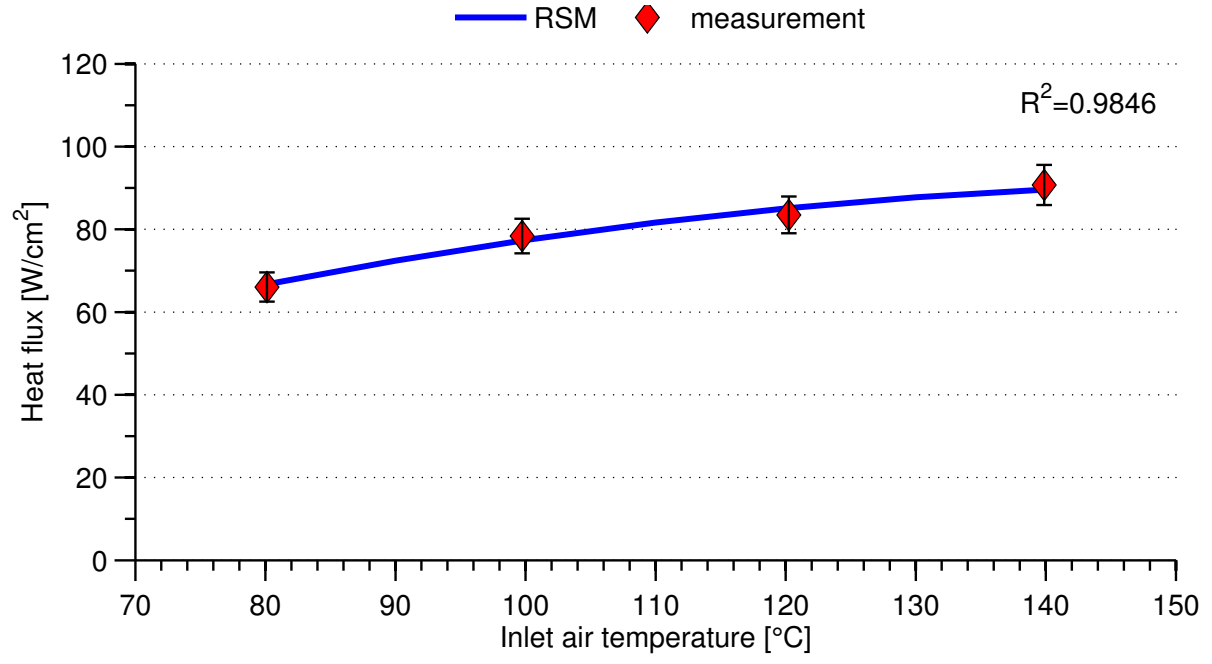

(b) Effect of the inlet air temperature

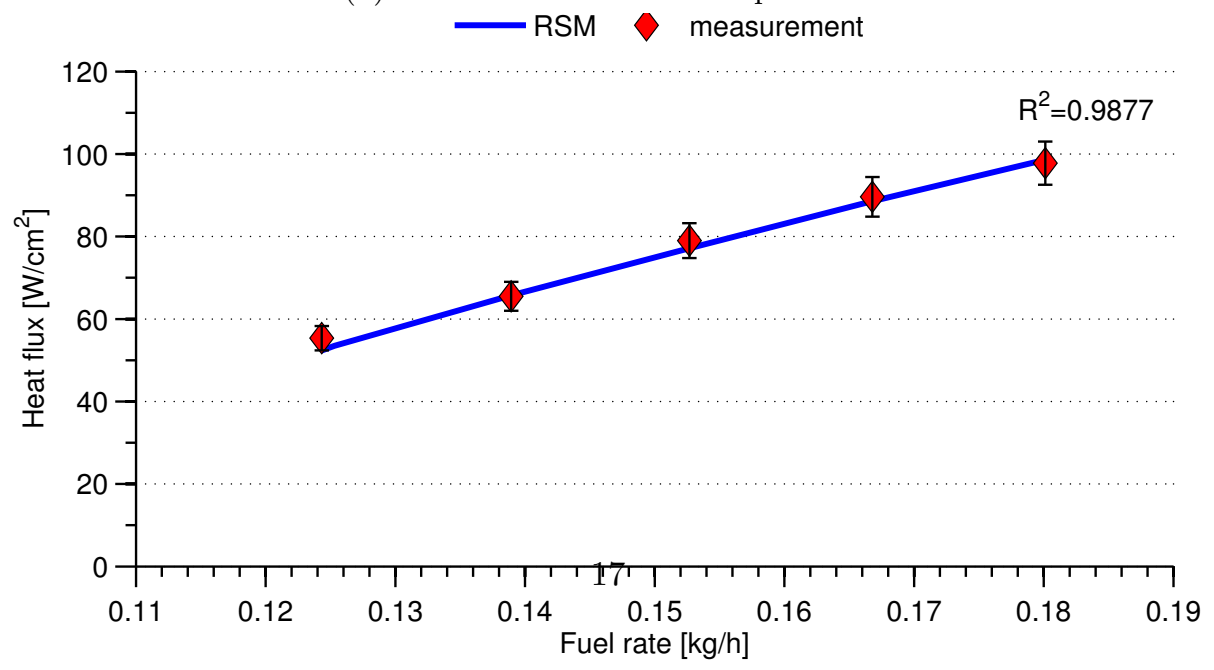

(c) Effect of the mass fuel rate

Figure 10: Effect of the engine settings on the peak heat flux 
Table 6: ANOVA table for fired operation

\begin{tabular}{c|c|c|c|c} 
Source term & DF & SS & $\mathrm{F}$ & $\mathrm{p}$ \\
\hline$\dot{m}_{f}$ & 1 & 2257.23 & 346.47 & 0.00 \\
$\mathrm{CR}$ & 1 & 1818.29 & 279.09 & 0.00 \\
$\mathrm{~T}$ & 1 & 535.90 & 82.26 & 0.00 \\
$\mathrm{CR} \cdot \mathrm{CR}$ & 1 & 141.56 & 21.73 & 0.00 \\
$\mathrm{~T} \cdot \mathrm{T}$ & 1 & 41.22 & 6.33 & 0.03 \\
\hline $\mathrm{CR} \cdot \dot{m}_{f}$ & 1 & 12.57 & 1.93 & 0.19 \\
$\mathrm{CR} \cdot \mathrm{T}$ & 1 & 8.08 & 1.24 & 0.29 \\
$\dot{m} f \cdot \dot{m}_{f}$ & 1 & 7.89 & 1.21 & 0.29 \\
$\mathrm{CR} \cdot \mathrm{T} \cdot \dot{m}_{f}$ & 1 & 3.37 & 0.52 & 0.48 \\
$\mathrm{~T} \cdot \dot{m}_{f}$ & 1 & 1.25 & 0.19 & 0.67 \\
\hline Lack of fit & 7 & 36.58 & 0.65 & 0.71 \\
Pure error & 6 & 48.11 & & \\
Total error & 13 & 84.69 & &
\end{tabular}

experimental design under fired operation. The instantaneous heat flux is the independent variable now. This does not require any additional measurements, since all the necessary data points can be determined from the instantaneous heat flux measured with the previous experimental design under fired operation. The levels of the crank angle are chosen to capture the combustion event. Top dead center is the factor's center point and the extreme levels are $340^{\circ} \mathrm{ca}$ and $380^{\circ} \mathrm{ca}$ (levels -2 and +2 ). These provide the widest possible range of the crank angle that does not fail the lack of fit test. The ANOVA results are listed in

380 Table 7 All the main and quadratic terms of the engine settings are significant. Furthermore, all the engine settings interact with the crank angle, indicating they all affect the instantaneous heat flux. Again, the interactions of the engine settings are not significant. The instantaneous heat flux is also a pure quadratic function of the crank angle around top dead center. However, Fig. 12 clearly

385 shows that this is not the case outside the crank angle window used to fit the model. A higher order polynomial is required instead of the proposed quadratic function. More levels of the crank angle were added to the design to construct a polynomial of the fourth degree. Nevertheless, the model was unable to predict the instantaneous heat flux outside the crank angle window used to fit the model and the ANOVA results remained the same for the engine settings. 


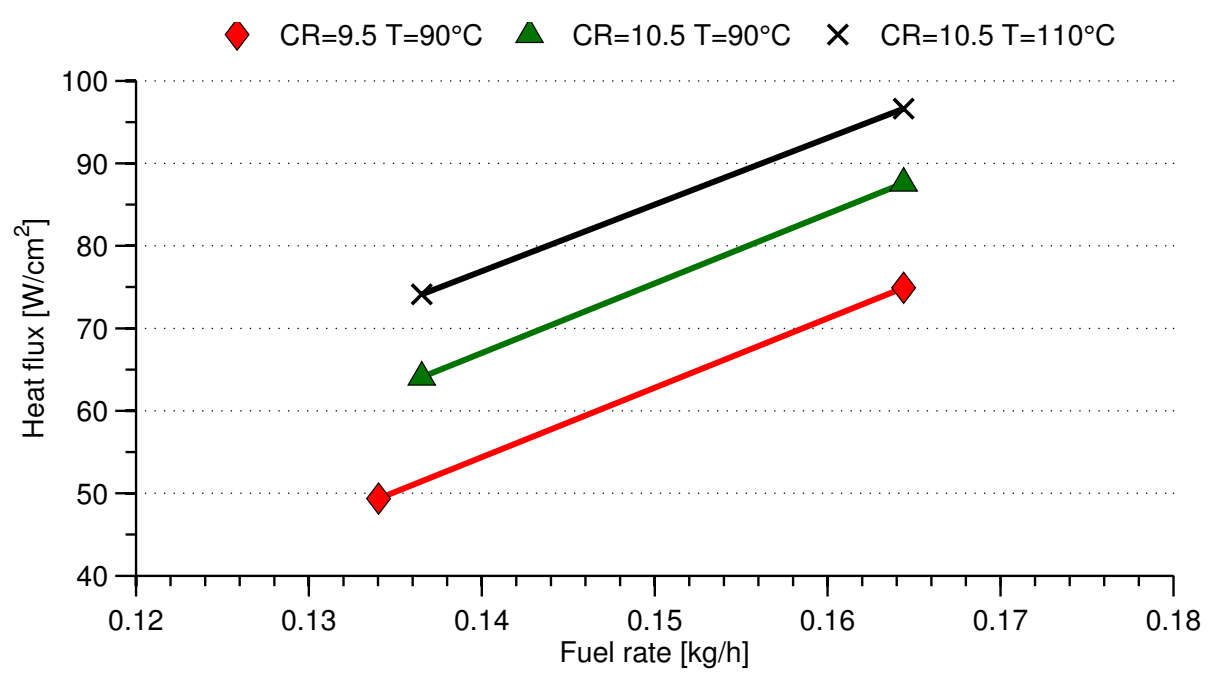

Figure 11: There is no visible interaction between the parameters

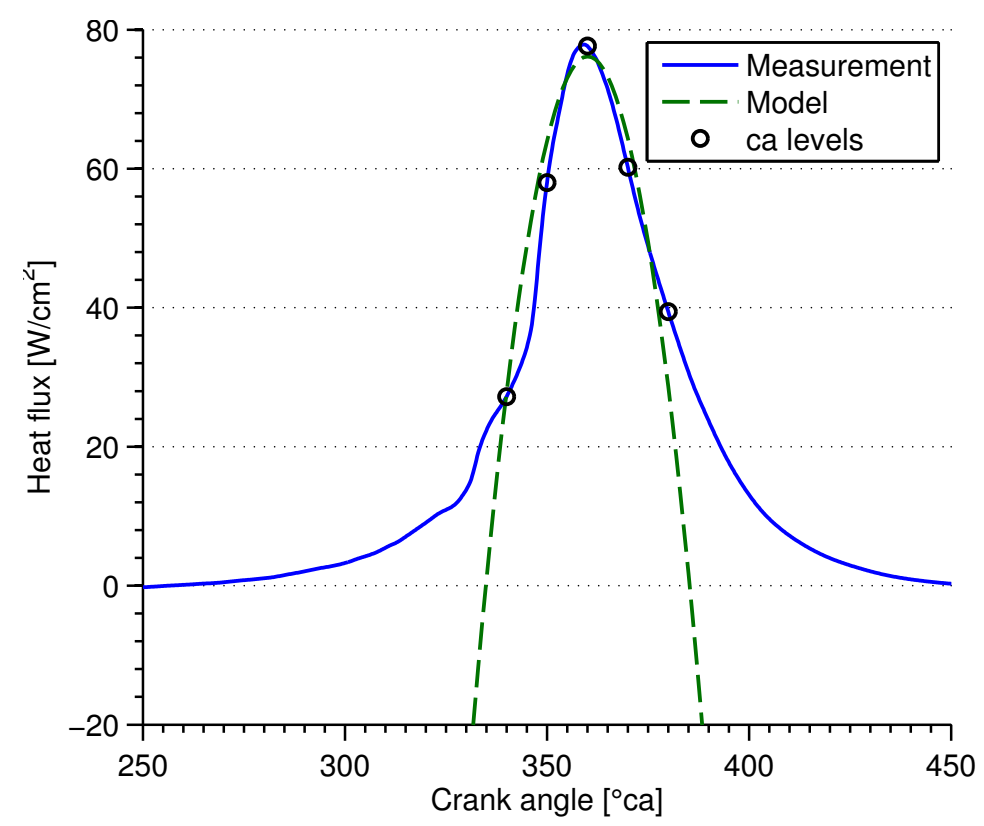

Figure 12: The modelled surface does not capture the effect of the crank angle outside the measurement window 
Table 7: ANOVA table for fired operation with the crank angle

\begin{tabular}{c|c|c|c|c} 
Factor & DF & SS & $\mathrm{F}$ & $\mathrm{p}$ \\
\hline $\mathrm{ca} \cdot \mathrm{ca}$ & 1 & 3973.23 & 208.92 & 0.00 \\
$\mathrm{CR}$ & 1 & 2498.37 & 131.37 & 0.00 \\
$\dot{m}_{f}$ & 1 & 2226.06 & 117.05 & 0.00 \\
$\mathrm{~T}$ & 1 & 791.87 & 41.64 & 0.00 \\
$\mathrm{CR} \cdot \mathrm{CR}$ & 1 & 362.41 & 19.06 & 0.00 \\
$\mathrm{CR} \cdot \mathrm{ca}$ & 1 & 197.77 & 10.40 & 0.01 \\
$\mathrm{~T} \cdot \mathrm{T}$ & 1 & 196.84 & 10.35 & 0.01 \\
$\mathrm{~T} \cdot \mathrm{ca}$ & 1 & 152.58 & 8.02 & 0.01 \\
$\dot{m_{f}} \cdot \dot{m}_{f}$ & 1 & 132.07 & 6.94 & 0.02 \\
$\dot{m_{f}} \cdot \mathrm{ca}$ & 1 & 110.75 & 5.82 & 0.03 \\
\hline $\mathrm{T} \cdot \dot{m}_{f} \cdot \mathrm{ca}$ & 1 & 54.24 & 2.85 & 0.12 \\
$\mathrm{CR} \cdot \mathrm{T} \cdot \dot{m}_{f} \cdot \mathrm{ca}$ & 1 & 25.68 & 1.35 & 0.27 \\
$\mathrm{~T} \cdot \dot{m}_{f}$ & 1 & 18.04 & 0.95 & 0.35 \\
$\mathrm{CR} \cdot \dot{m}_{f}$ & 1 & 11.76 & 0.62 & 0.45 \\
$\mathrm{CR} \cdot \dot{m}_{f} \cdot \mathrm{ca}$ & 1 & 11.38 & 0.60 & 0.45 \\
$\mathrm{CR} \cdot \mathrm{T} \cdot \dot{m}_{f}$ & 1 & 1.70 & 0.09 & 0.77 \\
$\mathrm{CR} \cdot \mathrm{T}$ & 1 & 1.44 & 0.08 & 0.79 \\
$\mathrm{ca}$ & 1 & 0.90 & 0.05 & 0.83 \\
$\mathrm{CR} \cdot \mathrm{T} \cdot \mathrm{ca}$ & 1 & 0.06 & 0.00 & 0.96 \\
\hline Lack of fit & 5 & 186.33 & 1.91 & 0.25 \\
$\mathrm{Pure}$ error & 8 & 60.90 & & \\
Total error & 13 & 247.23 & &
\end{tabular}

\section{Conclusion}

The purpose of this study was to investigate the effect of the engine settings on the wall heat flux. The heat flux was measured at the cylinder head and at three locations in the cylinder wall of a CFR engine. Under motored operation operation, on the other hand, the heat flux at the cylinder head is higher than at the cylinder wall during combustion. This is attributed to a higher convection coefficient at the head compared to the wall. Nevertheless, a heat release analysis confirms that the heat flux measurement at the cylinder head is sufficient to accurately capture the global heat transfer. A comparison of replicated operating points throughout the test day shows no effect of deposit formation on the measured heat flux. Two experiments were conducted and analysed according to Design of Experiments methods: one under motored operation and one under fired operation. It is found that the peak heat flux and total heat

405 released under motored operation are linear functions of the compression ratio only. The inlet air temperature does not affect the heat flux because its effect on the convection coefficient and the temperature difference between the gas and the wall cancel each other out. Under fired operation, the peak heat flux and peak convection coefficient are quadratic functions of the compression ratio 
and inlet air temperature and linear functions of the mass fuel rate. This is because the compressor ratio and the inlet air temperature affect the start of combustion. The interactions of the engine settings are not significant. For the total heat released, the compression ratio and inlet air temperature have a linear effect and the mass fuel rate has a quadratic effect, because it is proportional

415 to the energy content of the mixture. Adding the crank angle as an extra factor to the experimental design under fired operation, revealed that all the engine settings change the shape of the heat flux trace and that no interactions are significant.

\section{Appendix A}

\section{A.1 Heat release analysis}

In the heat release analysis, the first law of thermodynamics is applied to the combustion chamber, treated as a single-zone, during the closed part of the engine cycle [19]. The following energy balance can be written:

$$
\delta Q_{\text {fuel }}=d U_{s}+\delta W+\delta Q_{\text {heat }}
$$

With $\delta \mathrm{Q}_{\text {fuel }}$ the chemical energy released during the combustion, $\mathrm{dU}_{s}$ the change in sensible energy of the mixture, $\delta \mathrm{W}$ the work on the piston and $\delta \mathrm{Q}_{\text {heat }}$ the heat transfer from the gas to the cylinder walls. The effect of the crevices is neglected. The energy balance above can be rewritten as the heat release equation:

$$
\frac{d Q_{\text {fuel }}}{d \theta}=\frac{\gamma}{\gamma-1} p \frac{d V}{d \theta}+\frac{1}{\gamma-1} V \frac{d p}{d \theta}+\frac{d Q_{\text {heat }}}{d \theta}
$$

With $\gamma$ the heat capacity ratio, $\mathrm{p}$ the instantaneous cylinder pressure and $\mathrm{V}$ the instantaneous cylinder volume. The cylinder pressure is measured and the cylinder volume is derived from the engine geometry. The heat capacity ratio is calculated from the instantaneous specific gas constant $(R)$ and the instantaneous specific heat capacity at constant pressure $\left(c_{p}\right)$. R is constant from IVC until the start of the combustion and is calculated from the mass average of the

435 specific gas constants of the air, the fuel and the residual gases. From the end of the combustion until EVO, $\mathrm{R}$ is equal to that of the combustion products. The mixture composition of the reaction products is determined out of the reaction equations, assuming chemical equilibrium and taking into account dissociation according to the methods described by Heywood [19. During combustion, the specific gas constant is calculated with a linear interpolation between the value before and after combustion. The start and the end of the combustion are determined with an initial estimate for the rate of heat release analysis, in which $\gamma$ has a constant value of 1.35 . The specific heat capacity $c_{p}$ is determined as a function of the gas temperature with polynomials out of the DIPPR [28]

445 database and with the mixing rules described in [29. The first two terms on the right hand side of the equation are the net rate of heat release and represent the energy change due to the piston work and the change in sensible energy. The third term in the equation represents the energy lost as heat to the cylinder 
walls. This is obtained by multiplying the measured heat flux with the instantaneous area available for heat transfer. This energy balance makes it possible to validate the accuracy of the measurements. Integrating the heat release equation over the closed part of the engine cycle should equal the chemical energy of the fuel. This is the energy released during the combustion and it is determined as:

$$
Q_{f u e l}=\dot{m}_{f} \cdot L H V_{\text {fuel }} \cdot \eta_{\text {comb }}
$$

${ }_{455}$ With $\mathrm{LHV}_{\text {fuel }}$ the lower heating value of the fuel and $\eta_{\text {comb }}$ the combustion efficiency.

\section{Acknowledgements}

The authors of this paper like to acknowledge the technical assistance of Koen Chielens and Patrick De Pue. The research was carried out in the framework of a Ph.D. funded by starting Grant 01N03013 of Ghent University Special Research Fund (BOF) and later by grant SB-141289 of the Flemish Agency Innovation and Entrepreneurship (VLIAO). The experimental equipment is funded by a Research Grant (1.5.147.10N) of the Research Foundation - Flanders (FWO). The financial support is gratefully acknowledged.

\section{Abbreviations and definitions}

$\begin{array}{ll}\text { Abbreviations } \\ \text { ANOVA } & \text { analysis of variance } \\ \text { ATDC } & \text { after top dead center } \\ \text { BBDC } & \text { before bottom dead center } \\ \text { CA } & \text { crank angle } \\ \text { CFR } & \text { Cooperative Fuel Research } \\ \text { CR } & \text { compression ratio } \\ \text { DOE } & \text { design of experiments } \\ \text { DF } & \text { degrees of freedom } \\ \text { EGR } & \text { exhaust gas recirculation } \\ \text { EV } & \text { exhaust valve } \\ \text { EVC } & \text { exhaust valve closing time } \\ \text { EVO } & \text { exhaust valve opening time } \\ \text { HCCI } & \text { homogeneous charge compression ignition } \\ \text { IV } & \text { intake valve } \\ \text { IVC } & \text { intake valve closing time } \\ \text { IVO } & \text { intake valve opening time } \\ \text { LHV } & \text { lower heating value } \\ \text { ROHR } & \text { rate of heat release } \\ \text { RSM } & \text { response surface method } \\ \text { RTD } & \text { resistance temperature detector } \\ \text { SS } & \text { sum of squares }\end{array}$




$\begin{array}{ll}\text { Definitions } \\ \text { A } & \text { heat transfer surface area }\left[\mathrm{m}^{2}\right] \\ \eta_{\text {comb }} & \text { combustion efficiency }[-] \\ \gamma & \text { heat capacity ratio }[-] \\ \mathrm{h} & \text { convection coefficient }\left[\mathrm{W} / \mathrm{m}^{2} . \mathrm{K}\right] \\ \theta & \text { crank angle }\left[{ }^{\circ} \mathrm{ca}\right] \\ \mathrm{k} & \text { thermal conductivity }[\mathrm{W} / \mathrm{m} . \mathrm{K}] \\ \mathrm{L} & \text { characteristic length }[\mathrm{m}] \\ \dot{m}_{f} & \text { mass fuel rate }[\mathrm{kg} / \mathrm{h}] \\ \mathrm{p} & \text { in-cylinder pressure }[\mathrm{Pa}] \\ \mathrm{Q} & \text { global heat transfer }[\mathrm{W}] \\ \mathrm{Q}_{\text {heat }} & \text { cumulative heat transfer }[\mathrm{J}] \\ \mathrm{Q}_{\text {fuel }} & \text { chemical energy }[\mathrm{J}] \\ \mathrm{Q}_{R O H R} & \text { cummulative heat release rate }[\mathrm{J}] \\ \mathrm{Q}_{\text {tot }} & \text { total energy released }[\mathrm{J}] \\ \mathrm{q} & \text { instantaneous heat flux }\left[\mathrm{W} / \mathrm{m}^{2}\right] \\ \mathrm{T} & \text { temperature }[\mathrm{K}] \\ \mathrm{U}_{s} & \text { sensible energy }[\mathrm{J}] \\ \mathrm{V} & \text { characteristic velocity }[\mathrm{m} / \mathrm{s}] \\ \mathrm{V} & \text { in-cylinder volume }\left[\mathrm{m}^{3}\right] \\ \mathrm{W} & \text { work }[\mathrm{J}] \\ \mu & \text { dynamic viscosity }\left[\mathrm{N} . \mathrm{s} / \mathrm{m}^{2}\right] \\ \rho & \text { density }\left[\mathrm{kg} / \mathrm{m}^{3}\right]\end{array}$

\section{References}

[1] S. Onishi, S. Jo, P. Shoda, P. Jo, S. Kato, Active thermo-atmosphere combustion (ATAC): A new combustion process for internal combustion engines, SAE Technical paper 790501 (1979).

[2] P. Najti, D. Foster, Compression-Ignited Homogeneous Charge Combustion, SAE Technical paper 830264 (1983).

[3] M. Christensen, B. Johansson, P. Einewall, Homogeneous charge compression ignition (HCCI) using isooctane, ethanol and natural gas - a comparison with spark ignition operation, SAE Technical paper 972874 (1997).

[4] H. Pfriem, Der Wärmeübergang bei schnellen Druckänderungen in gasen besonders in Versuchseinrichtungen zur Messung des Zündverzuges, Forschung auf dem Gebiete des Ingenieurwesens 13 (4) (1942) 150-164.

[5] K. Elser, Instationäre Wärmeübertragung bei periodisch adiabater Verdichtung turbulenter Gase, Forschung auf dem Gebiete des Ingenieurwesens 21 (3) (1955) 65-74.

[6] A. Alkidas, J. Myers, Transient heat-flux measurements in the combustionchamber of a spark-ignition engine, Journal of Heat Transfer-Transactions of the ASME 104 (1) (1982) 62-67. 
[7] A. Wimmer, R. Pivec, T. Sams, Heat transfer to the combustion chamber and port walls of IC engines - measurement and prediction, SAE Technical paper 2000-01-0568 (2000).

[8] D. L. Boggs, Spatially-resolved measurements of instantaneous engine heat flux, Ph.d. thesis (1990).

[9] J. Chang, O. Gralp, Z. Filipi, D. Assanis, T.-W. Kuo, P. Najt, R. Rask, New heat transfer correlation for an HCCI engine derived from measurements of instantaneous surface heat flux, SAE Technical paper 2004-01-2996 (2004).

[10] J. Chang, Z. Filipi, T.-W. Kuo, D. Assanis, P. Najt, R. Rask, Investigation of mixture preparation effects on gasoline HCCI combustion aided by measurements of wall heat flux, J. Eng. Gas Turbines Power 130 (3) (2008) 062806-1 062806-9.

[11] S. Hensel, F. Sarikoc, F. Schumann, H. Kubach, U. Spicher, Investigations on the heat transfer in HCCI gasoline engines, SAE Technical paper 200901-1804 (2009).

[12] S. Hensel, Modellierung der Verbrennung und des Wandwärmeübergangs in Ottomotoren met homogen kompressionsgezündeter Verbrennung, Ph.d. thesis (2009).

[13] M. Heinle, Ein verbesserter Berechnungsansatz zur Bestimmung der instationären Wandwärmeverluste in Verbrenningsmotoren, Ph.d. thesis (2013).

[14] P. Berger, Experimental Design with Applications in Management, Engineering, and the Sciences, Duxbury, Belmont, USA, 2002.

[15] R. Mason, R. Gunst, L. James, Statistical Design and Analysis of Experiments: With Applications to Engineering and Science, J. Wiley, New York, 2003.

[16] J. Demuynck, M. De Paepe, H. Huisseune, R. Sierens, J. Vancoillie, S. Verhelst, Investigation of the influence of engine settings on the heat flux in a hydrogen- and methane-fueled spark ignition engine, Applied Thermal Engineering 31 (2011) 1120-1228.

[17] J. Taylor, An introduction to error analysis: the study of uncertainties in physical measurements, University Science Books, 1982.

[18] T. De Cuyper, J. Demuynck, S. Broekaert, S. Verhelst, M. De Paepe, Heat transfer in premixed spark ignition engines part II: Systematic analysis of the heat transfer phenomena, Submitted to Energy.

[19] J. Heywood, Internal Combustion Engine Fundamentals, McGraw-Hill, 1988. 
[20] O. Güralp, M. Hoffman, D. Assanis, Z. Filipi, T.-W. Kuo, P. Najt, R. Rask, Characterizing the effect of combustion chamber deposits on a gasoline HCCI engine, SAE Technical paper 2006-01-3277 (2006).

[21] O. Güralp, M. Hoffman, D. Assanis, Z. Filipi, T.-W. Kuo, P. Najt, R. Rask, Thermal characterization of combustion chamber deposits on the HCCI engine piston and cylinder head using instantaneous temperature measurements, SAE Technical paper 2009-01-0668 (2009).

[22] O. Güralp, P. Najt, Z. Filipi, Method for determining instantaneous temperature at the surface of combustion chamber deposits in an HCCI engine, J. Eng. Gas Turbines Power 135 (8) (2013) 0815011-08150114.

[23] J. Demuynck, A fuel independent heat transfer correlation for premixed spark ignition engines, Ph.d. thesis (2012).

[24] S. Broekaert, J. Demuynck, T. De Cuyper, S. Verhelst, M. De Paepe, Heat transfer in premixed spark ignition engines part I: Identification of the factors influencing heat transfer, Submitted to Energy.

[25] J. Welty, C. Wicks, R. Wilson, G. Rorrer, Fundamentals of Momentum, Heat and Mass transfer, 4th Edition, John Wiley and Sons, New York, 2001.

[26] W. Annand, Heat transfer in the cylinders of reciprocating internal combustion engines, Proc Instn Mech Engrs 177 (36) (1963) 973-996.

[27] G. Woschni, A universally applicable equation for the instantaneous heat transfer coefficient in the internal combustion engine, SAE Technical paper 670931 (1967).

[28] R. Rowley, W. Wilding, J. Oscarson, Y. Yang, N. Zundel, T. Daubert, R. Danner, DIPPR Data Compilation of Pure Compound Properties, Design Institute for Physical Properties, AIChE, New York, 2003.

[29] R. Reid, J. Prausnitz, B. Poling, The properties of Gases and Liquids, McGraw-Hill Book Co., Singapore, 1988. 